\title{
Correction to: Revitalizing the Concept of Public Procurement for Innovation (PPI) from a Systemic Perspective: Objectives, Policy Types, and Impact Mechanisms
}

\author{
Kiyoon Shin ${ }^{1} \cdot$ Yeongjun Yeo ${ }^{1} \cdot$ Jeong-Dong Lee ${ }^{1}$
}

Published online: 24 July 2019

C) Springer Science+Business Media, LLC, part of Springer Nature 2019

\section{Correction to: Systemic Practice and Action Research https://doi.org/10.1007/s11213-019-09488-7}

The presentation of figures in the manuscript in the online version has some errors. Figures were mixed-up. Figure 2 was missing, Figure 2 presented in the original proof published should be moved and numbered as the Figure 3.

With this, the correct figures are hereby published.

The online version of the original article can be found at https://doi.org/10.1007/s11213-019-09488-7

Yeongjun Yeo

yyj913@snu.ac.kr

Kiyoon Shin

kiryoon92@snu.ac.kr

Jeong-Dong Lee

leejd@snu.ac.kr

1 Technology Management, Economics and Policy Program, Seoul National University, Gwanak-gu, Seoul 151-742, Republic of Korea 


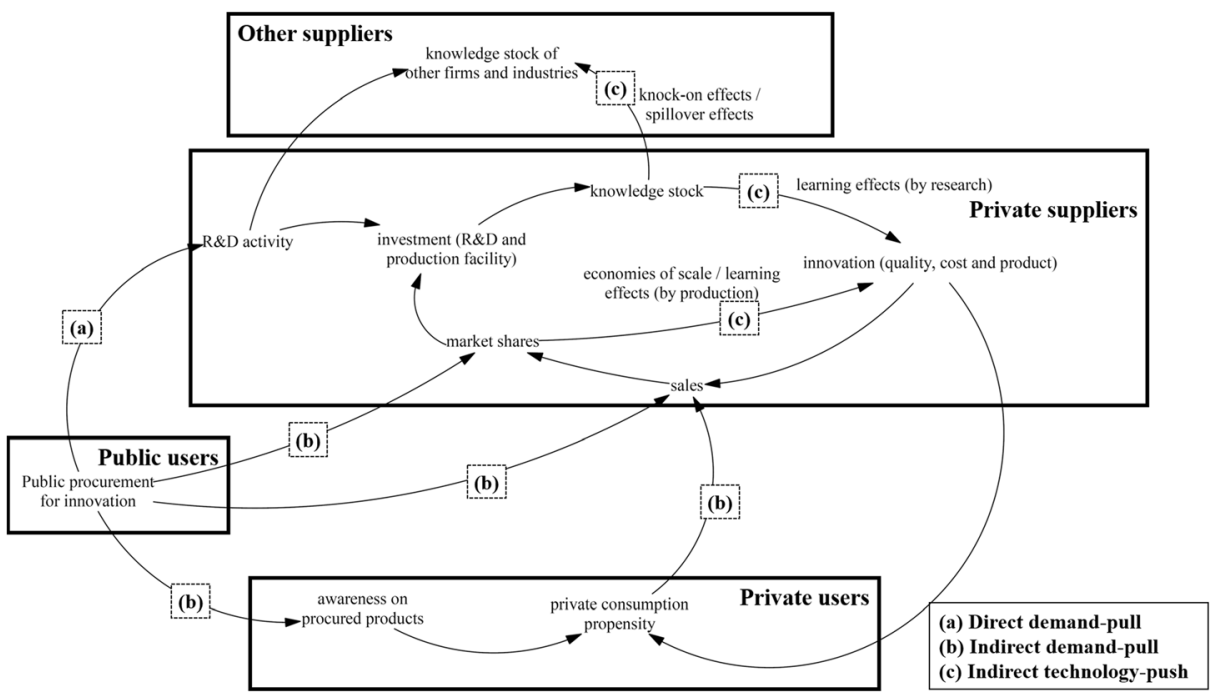

Fig. 2 Causal loop diagram of PPI-induced impact channels

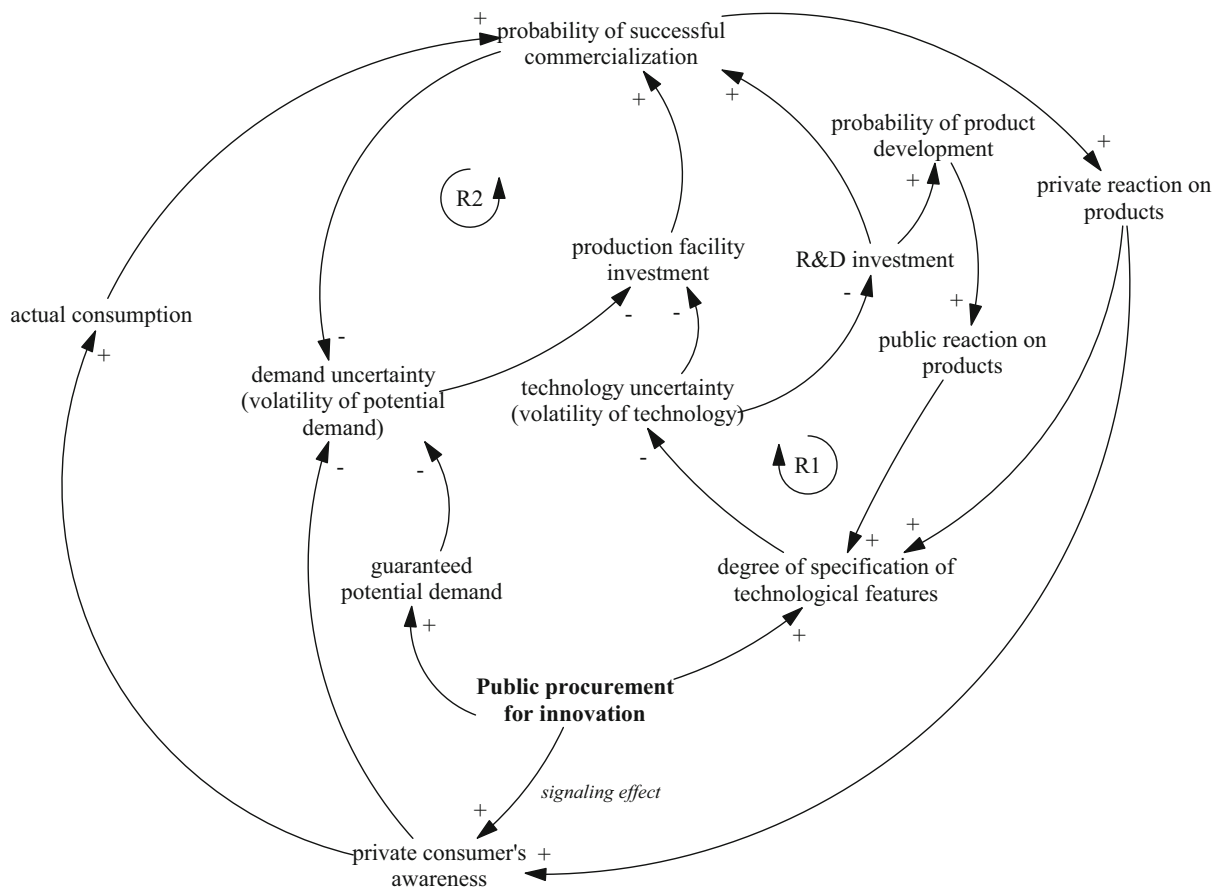

Fig. 3 Causal loop diagram for pre-commercial PPI's policy impact channels

The original article has been corrected

Publisher's Note Springer Nature remains neutral with regard to jurisdictional claims in published maps and institutional affiliations. 